\title{
Can a genetic signature for metastatic head and neck squamous cell carcinoma be characterised by comparative genomic hybridisation?
}

\author{
HS Patmore', NE Ashman James', L Cawkwell', A MacDonald ${ }^{2}$, ND Stafford' and J Greenman*,1,3 \\ 'Postgraduate Medical Institute of the University of Hull, Hull and York Medical School, University of Hull, Cottingham Road, Hull HUI6 5JQ, UK; \\ ${ }^{2}$ Department of Histopathology, Hull Royal Infirmary, Anlaby Road, Hull HU3 2JZ, UK
}

Survival from head and neck squamous cell carcinoma (HNSCC) has remained static for the last 20 years. The development of lymph node metastasis $(\mathrm{LNM})$ significantly reduces the 5-year survival rate, thus the ability to identify tumours with the potential to metastasise would allow more aggressive treatment regimes to be directed at these patients regardless of negative clinical and radiological findings at the time of presentation. Comparative genomic hybridisation $(\mathrm{CGH})$ can identify chromosomal aberrations that may lead to metastasis. DNA from 23-paired specimens of primary tumour (PT) and LNM were analysed. Nonrandom copy number changes were identified in all paired samples. Similar numbers of aberrations were identified on PT and LNM samples. The most common aberrations were 3q (90\%), 8q (65\%), Iq (50\%), 5p (43\%), 2q (4I\%) and II q (4I\%) and deletions 3p (57\%), Ip (54\%), $4 p(48 \%), 13 q(48 \%), I \mid q(4 \mid \%)$ and I Oq (37\%). A number of differences were also detected. No aberration was found to be preferentially associated with the LNM, although gains on 6q (48 vs 22\%) and 22q (26 vs 9\%) were found at higher frequencies. Clonality studies demonstrated that LNM develop from the dominant population of cells in the PT. These results were compared with two similar publications. No combination of chromosomal aberrations, as detected by $\mathrm{CGH}$, was associated with metastatic progression in HNSCC.

British Journal of Cancer (2004) 90, 1976-1982. doi:10.1038/sj.bjc.660I756 www.bjcancer.com

Published online 13 April 2004

(c) 2004 Cancer Research UK

Keywords: comparative genomic hybridisation; head and neck cancer; metastasis

Head and neck squamous cell cancer (HNSCC) is a major health problem worldwide accounting for significant morbidity and mortality. The survival rate over the last 20 years has not improved appreciably despite a number of new and refined treatment modalities. Although many different prognostic indicators have been studied, the occurrence of nodal metastasis at presentation remains the single most important factor, decreasing the 5-year survival rate from approximately 75 to $29 \%$ (Ono, 1986). The identification of tumours with metastatic potential prior to the occurrence of detectable nodal spread would allow more aggressive primary treatment regimes to be instigated and directed at regional as well as local control.

Genetic studies have begun to characterise the chromosomal abnormalities involved in HNSCC. However, relatively little is known about the genetic aberrations associated with the metastatic event. Comparative genomic hybridisation (CGH) is a powerful technique that screens the entire genome for regions of DNA sequence copy number alterations. Comparative genomic hybri-

*Correspondence: Dr J Greenman, E-mail: J.Greenman@hull.ac.uk

${ }^{3} \mathrm{Dr} J$ Greenman's Current address: Medical Research Laboratory, Wolfson Building, University of Hull, Cottingham Road, Hull HU6 7RX, UK

Received 7 August 2003; revised 7 December 2003; accepted 10 February 2004; published online 13 April 2004 disation has previously been applied in several HNSCC studies and has demonstrated a nonrandom pattern of genomic aberrations commonly showing deletions of material from $3 p, 4 q, 5 q, 9 p, 18 q$ and gains involving 3q, 5p, 7p, 8q, 11q, 17q and 20q (Struski et al, 2002). Although a number of tumour progression models have been constructed, based on the frequency of these aberrations (Bockmuhl et al, 2002; Huang et al, 2002), there has been no clear pattern of mutations that lead to metastasis.

An additional level of complexity is found in HNSCC due to the coexistence of karyotypically unrelated clones (Veltman et al, 1998; Jin et al, 2002). The presence of multiple clones with differing phenotypic characteristics within the primary can make identification and analysis of the metastatically competent cells very difficult.

Only a few studies have looked at the direct comparison between complete karyotypes of HNSCC primary tumour (PT) and the related lymph node metastases (LNM) (Kujawski et al, 1999; Bockmuhl et al, 2002). Kujawski et al (1999) compared data from CGH analysis of 19 paired laryngeal SCC PT and LNM. Out of 17 analysed pairs, the most common copy number changes on both primary tumour and metastasis were found on 3p, 3q, 5p, 9 and 13 . Losses on chromosomes $13,8 p$ and $9 q$ were found more frequently on the LNM than the PT. Welkoborsky et al (2000) analysed 20 patient -10 node-negative and 10 node-positive (both primary and lymph node samples) oropharyngeal and hypopharyngeal squamous cell carcinoma (SCC). Over-representations, as defined 
by these authors, of $21 \mathrm{q}$ and $22 \mathrm{q}$ were found in both PT and LNM. Gains of 1q, 8q, 11q, 18q and 19p were more frequent in the LNM, whereas a gain on $11 p$ and a loss on $17 p$ were only found in the LNM. Unfortunately, the results from Welkoborsky et al (2000) could not be used for comparative purposes, as the raw data were not shown in the publication. Bockmuhl et al (2002) investigated 54 patients: 34 matched HNSCC pairs and 20 nonmetastasising HNSCC samples. The clonal relationship between the PT and LNM, that is, evidence of the LNM originating from the PT was evaluated using three mathematical models, revealing concordance in 64$68 \%$ of the matched pairs. Of the paired samples, gains on $11 \mathrm{q} 13$, $7 \mathrm{q} 11.2,1 \mathrm{q} 21-\mathrm{q} 22$ and deletions on $8 \mathrm{p}, 11 \mathrm{p} 14$-qter, 10p12, 10q and 14 were associated with metastasis. Owing to the relatively low numbers of matched HNSCC (PT and LNM) that have been analysed, we describe the second largest cohort of CGH data for primary HNSCC and their corresponding lymph nodes. The possibility of identifying potential genetic aberrations that lead to metastasis is discussed after combining our data with the results of the two previous studies.

\section{MATERIALS AND METHODS}

\section{Tissue samples}

Tissue samples were collected from 23 patients (17 male and six female) undergoing surgery for HNSCC at the Department of Otolaryngology and Head and Neck Surgery, Hull Royal Infirmary between 1997 and 2002. All biopsies were collected from patients undergoing composite resections for oral cavity and oropharyngeal tumours, or total laryngectomy with or without partial pharyngectomy for tumours of the laryngopharynx. In each case, the LNM and primary biopsy were taken at the same time and no second primary was evident in any of the cases. There was neither a history of previous malignancy nor had any of the patients received treatment prior to surgical resection. A consultant pathologist (A.M) confirmed all samples to be SSC and all tumours were staged according to UICC guidelines. The Hull and East Yorkshire Research Ethics Committee approved the study and informed, written consent was obtained from all patients. Samples were immediately snap frozen in liquid nitrogen at the time of resection and stored at $-80^{\circ} \mathrm{C}$. The clinicopathological details of all patients are summarised in Table 1 . For each sample, a $10 \mu \mathrm{m}$ tissue section was cut adjacent to the extracted section. These were stained with haematoxylin and eosin to assess normal to tumour cell ratio; greater than $70 \%$ tumour cell content was needed for CGH analysis.

\section{Comparative genomic hybridisation}

DNA was extracted from 20 serial $20 \mu$ m cryostat sections, or using the whole biopsy by proteinase $\mathrm{K}$ digestion followed by phenolchloroform extraction. DNA quality and purity were assessed by electrophoresis and spectrophotometry at $260 \mathrm{~nm}$ and CGH performed essentially as described previously (Stafford et al, 1999). All CGH reagents were obtained from Vysis Ltd (Maidenhead, UK). All experiments were performed in combination with both positive (DNA with known aberrations) and negative (normal: normal hybridisation) control experiments. Sex mismatching of test and reference DNA precluded the analysis of the sex chromosomes. Deletions and gains of DNA were identified whenever the CGH ratio profile exceeded thresholds established through normal: normal hybridisations ( 0.85 and 1.15 , respectively).

\section{Analysis}

The presence of each aberration was scored independently, that is, gains and deletions were considered separately. Multiple gains or deletions on the same arm were interpreted depending on the site,
Table I Patients clinicopathological details

\begin{tabular}{|c|c|c|c|c|c|}
\hline $\begin{array}{l}\text { Patient } \\
\text { no. }\end{array}$ & $\begin{array}{c}\text { Age } \\
\text { (years) }\end{array}$ & Tumour site & T stage & $\mathbf{N}$ stage & Differentiation \\
\hline । & 58 & Hypopharynx & 4 & 2 & Poor \\
\hline 2 & 53 & Hypopharynx & 4 & 3 & Poor \\
\hline 3 & 55 & Larynx & 4 & $2 c$ & Poor \\
\hline 4 & 55 & Hypopharynx & I & 2 & Poor \\
\hline 5 & 54 & Oropharynx & 4 & I & Moderate \\
\hline 6 & 65 & Larynx & 3 & I & Moderate \\
\hline 7 & 70 & Larynx & 2 & I & Well \\
\hline 8 & 50 & Hypopharynx & 4 & $2 b$ & Poor \\
\hline 9 & 67 & Hypopharynx & 4 & 2 & Poor \\
\hline 10 & 52 & Larynx & 4 & $2 c$ & Poor \\
\hline | | & 71 & Larynx & 4 & I & Moderate \\
\hline 12 & 57 & Oropharynx & 2 & 2 & Poor \\
\hline 13 & 65 & Oropharynx & 4 & $2 b$ & Moderate \\
\hline 14 & 67 & Hypopharynx & 3 & $2 a$ & Poor \\
\hline 15 & 55 & Hypopharynx & 3 & $2 a$ & Moderate \\
\hline 16 & 61 & Larynx & 3 & $2 b$ & Poor \\
\hline 17 & 48 & Larynx & 3 & 1 & Mod \\
\hline 18 & 65 & Hypopharynx & 2 & 2 & Poor \\
\hline 19 & 44 & Larynx & 2 & 2 & Moderate \\
\hline 20 & 72 & Hypopharynx & 4 & I & Poor \\
\hline 21 & 56 & Larynx & 4 & 2 & Poor \\
\hline 22 & 76 & Larynx & 4 & 2 & Moderate \\
\hline 23 & 61 & Larynx & 4 & $2 c$ & Moderate \\
\hline
\end{tabular}

$\mathrm{T}$ stage $=$ tumour stage; $\mathrm{N}$ stage $=$ nodal stage.

size and amplification involved according to the guidelines in Zitzelsberger et al, (1997) and Jeuken et al, (2002).

\section{Clonal relationship}

If the LNM originated from the dominant cell population within the PT, similarities between the copy number changes and their location would be expected. Based on this expectation, Alejandro Schaffer developed a probabilistic model to quantify the association between two matched tumour samples (Kuukasjarvi et al, 1997).

The occurrence of an aberration was weighted depending on its frequency in the entire population. Aberrations common to both paired samples could then be used to evaluate the clonality. 'This model uses only data from shared abnormalities and assumes that the paired specimens must be both losses or both gains, and that the breakpoint along the chromosome arm is the same' (Kuukasjarvi et al, 1997).

\section{Statistical analysis}

If there is a clonal relationship between the two groups of specimens, the occurrence of an aberration in the primary would alter the expectation of its presence in the LNM, thus McNemar's test was applied to evaluate the significance of the individual aberrations. $\chi^{2}$ or Fisher's exact test, as appropriate, was also used so that the comparison with other publications could be performed.

\section{RESULTS}

Comparative genomic hybridisation analysis of our 46 samples revealed a mean of 18 (range 5-36) and 19 (range 7-43) aberrations in the PT and LNM, respectively. From these data, a mean of 11 aberrations were found common to both samples. The follow-up and survival data from these patients have been discussed previously (Ashman et al, 2003). 
Table 2 Frequency of chromosomal aberrations found in greater than $30 \%$ of the specimens analysed

\begin{tabular}{|c|c|c|c|c|c|c|c|}
\hline \multirow[b]{2}{*}{ Location } & \multirow[b]{2}{*}{ Gain/deletion } & \multicolumn{2}{|c|}{$\begin{array}{l}\text { Frequency } \\
\quad(n=23)\end{array}$} & \multicolumn{2}{|c|}{$\begin{array}{l}\text { Bockmuhl } \\
\text { et al }(2002) \\
(n=34)\end{array}$} & \multicolumn{2}{|c|}{$\begin{array}{c}\text { Kujawski } \\
\text { et al (I999) } \\
(n=17)\end{array}$} \\
\hline & & $\% \mathbf{P T}$ & $\begin{array}{c}\% \\
\text { LNM }\end{array}$ & $\% \mathbf{P T}$ & $\begin{array}{c}\% \\
\text { LNM }\end{array}$ & $\% \mathbf{P T}$ & $\begin{array}{c}\% \\
\text { LNM }\end{array}$ \\
\hline $3 q 26-27$ & Gain & 78 & 87 & 80 & 85 & 59 & 71 \\
\hline 3p25-pter & Deletion & 52 & 43 & 83 & 80 & 53 & 41 \\
\hline 5q34-qter & Deletion & 52 & 39 & 50 & 70 & 6 & 12 \\
\hline Ip34.2-pter & Deletion & 43 & 39 & 65 & 27 & 0 & 0 \\
\hline 5pl5.1-pter & Gain & 43 & 22 & 50 & 50 & 35 & 29 \\
\hline||$q \mid 3.3-13.5$ & Gain & 39 & 26 & 65 & 80 & 47 & 53 \\
\hline | | q23.3 & Deletion & 39 & 30 & 65 & 58 & 21 & 32 \\
\hline$|2 p| 2.3-13 . \mid$ & Gain & 39 & 26 & 40 & 50 & 29 & 12 \\
\hline $2 q 31$ & Gain & 39 & 35 & 60 & 48 & 6 & 6 \\
\hline $3 q 24$ & Gain & 39 & 65 & 80 & 60 & 41 & 35 \\
\hline $8 q 21.3$ & Gain & 39 & 30 & 50 & 50 & 0 & 18 \\
\hline $8 q 23$ & Gain & 39 & 57 & 60 & 80 & 6 & 18 \\
\hline |8p| |.31-pter & Gain & 35 & 26 & 23 & 20 & 0 & 5 \\
\hline $3 p \mid 4.1-3$ & Deletion & 35 & 39 & 85 & 87 & 71 & 59 \\
\hline $6 q 12$ & Gain & 35 & 39 & 55 & 35 & 0 & 6 \\
\hline 10q26.1-qter & Deletion & 30 & 35 & 45 & 38 & 5 & 5 \\
\hline |3q31 & Deletion & 30 & 43 & 85 & 67 & 47 & 71 \\
\hline $4 p 16$ & Deletion & 30 & 43 & 55 & 60 & 29 & 35 \\
\hline $8 p 22$ & Deletion & 30 & 30 & 55 & 60 & 6 & 24 \\
\hline$|q 3|$ & Gain & 26 & 30 & 40 & 43 & 24 & 24 \\
\hline $7 q 31.1-3$ & Gain & 26 & 30 & 44 & 38 & 5 & 16 \\
\hline $12 q 22$ & Gain & 22 & 30 & 45 & 37 & 6 & 0 \\
\hline |q21.2 & Gain & 22 & 30 & 75 & 65 & 24 & 24 \\
\hline 19p|3.3-pter & Deletion & 17 & 30 & 15 & 63 & 0 & 0 \\
\hline $4 q 26$ & Gain & 17 & 30 & 77 & 27 & 0 & 0 \\
\hline $4 q 34$ & Deletion & 17 & 35 & 70 & 55 & 18 & 24 \\
\hline $6 q 22$ & Gain & 17 & 35 & 50 & 50 & 0 & 0 \\
\hline $5 q 13$ & Deletion & 13 & 35 & 69 & 75 & 32 & 37 \\
\hline $9 p 24$ & Deletion & 13 & 30 & 56 & 69 & 42 & 47 \\
\hline $13 q 22$ & Gain & 9 & 30 & 85 & 70 & 0 & 5 \\
\hline
\end{tabular}

It should be noted that the percentage shown in Bockmühl's series is the maximum percentage found at any particular location read from the histogram provided on http://amba.charite.de/cgh. PT = primary tumour; LNM = lymph node metastasis.

The most frequent aberration was found to be a gain on $3 \mathrm{q}$, observed in 21 out of the 23 patients (91\%), more precisely the loci $3 \mathrm{q} 25-\mathrm{q} 27$ in 20 of the 23 of the PT (87\%), and 21 of the 23 LNM $(91 \%)$. Table 2 summarises the frequent aberrations, greater than $30 \%$ found in either or both of the matched specimens. For comparison, the data from Bockmühl's and Kujawski's series are included in Table 2.

A mean of seven and eight aberrations were found to be unique to either PT or LNM, respectively. The most common unique aberration found throughout the metastatic samples was a gain on $6 \mathrm{q}$ present in nine of $23(39 \%)$ lymph nodes. This gain was found in four other lymph nodes, but also in their relevant PT; two PT had unique aberrations on 6q. The gains on $6 \mathrm{q}$ were further located to two independent loci, $6 \mathrm{q} 13$ and $6 q 22.3$. A gain on $22 \mathrm{q}$ was unique to the LNM at a slightly lower frequency-six of $23(26 \%)$. One matched pair and one PT independent of its lymph node expressed this aberration as well. Other frequent findings unique to the lymph nodes were gains on $1 \mathrm{q}, 7 \mathrm{q}, 13 \mathrm{q}$ and deletions on $1 \mathrm{p}$. McNemar's and Fisher's exact tests did not find any significant differences between the expression of specific locations in either PT and LNM genotypes.

The chromosomal locations of all of the aberrations are shown in Tables 3 and 4 . Figures 1 and 2 depict the location of all of the chromosomal gains and losses found in our patients.
The clonal relationships (CR) between primaries and LNMs were evaluated according to a probabilistic model. These results showed a strong $\mathrm{CR},>95 \%$ concordance in all but one case.

\section{DISCUSSION}

CGH screens the entire genome for DNA copy number alterations, and thus yields vast quantities of information. Analysis of this information from a matched primary tumour and lymph node provides a clear picture of the presence or absence of a CR. In our study, a strong CR was found in all but one case, strongly suggesting that the cells, which were found in the lymph nodes, originate from the dominant cell population in their corresponding primary tumours.

Our cohort of patients was similar to Bockmühl's series, that is, all samples were HNSCC taken from patients with no history of previous malignancy or treatment such as radiotherapy. The cohort of 23 patients reported here is the second largest group to be studied: Bockmühl's series contained 34 patients. Kujawski's cohort (19 patients) matched the same patient criteria but limited the site to larynx. Comparison of our findings show that the frequency of $3 \mathrm{q} 25-\mathrm{q} 27,5 \mathrm{p}, 11 \mathrm{q} 13-\mathrm{q} 14.1$ and $1 \mathrm{q} 31$ gains are the same as reported previously (Bockmuhl et al, 1998; Bergamo et al, 2000; Gollin, 2001). Our results were also very similar to Kujawski et al (1999) with respect to gains at $3 \mathrm{q} 22-\mathrm{q} 24,8 \mathrm{q} 24$ and deletions at 3p22-p25, 4p15.3-pter, 4q33-qter, 7q22 and 18q23. Bockmühl's series (2000) revealed a higher incidence of all these aberrations, which could be explained by different and/or more sensitive CGH analysis software. Interestingly, in our and Bockmühl's cohort, aberrations were found that were absent in Kujawski's series, for example, deletions at 1p34.2-pter (found in $43.5 \%$ of the PT and $39.1 \%$ of the LNM in our cohort, and 65 and 27\%, respectively, in Bockmühl's cohort) and 19p13.3-pter (found in $17.4 \%$ of PT samples and $30.4 \%$ of LNM in our cohort, and 15 and $63 \%$, respectively, in Bockmühl's cohort). The significance of these differences is unclear, but they seem to highlight the need for analysis of specific subsites of HNSCC to clarify whether these genetic variations reflect different anatomical locations and if so their potential as diagnostic markers. This study, although reporting one of the largest HNSCC cohorts, becomes relatively small if subdivided by anatomical site or staging; therefore, such analysis was not undertaken.

The similar number of unique random aberrations in both the primary and LNM samples could be explained by continued clonal evolution after the divergence of the metastatic cells. If this is the case, the unique changes in the primary tumour are most likely to be incidental to the metastatic progression. Therefore, the common aberrations found in both paired samples as well as the unique changes in the LNM probably underlie the tumour cell's ability to metastasise and proliferate.

Our data show associations between gains of chromosomal material on $6 \mathrm{q}$ and $22 \mathrm{q}$ in the LNM and not in the primary tumour samples. Detailed analysis of the location of the DNA gain on $6 \mathrm{q}$ show two frequent areas $-6 \mathrm{q} 13$ and $6 \mathrm{q} 22.3$, both more frequent in the LNM than PT, but not of statistical significance $(P=0.2$ and 0.11 , respectively). There were also more LNM samples with gains of DNA material on 22q. Bockmühl's cohort (along with Welkoborsky et al, 2000) found equal numbers of $22 \mathrm{q}$ aberrations between PT and LNM, whereas Kujawski had very few in either sample (Table 2). Although the difference in the expression of this gain on $22 \mathrm{q}$ was not statistically significant in our cohort (McNemar's test $P=0.07$, Fisher's exact test $P=0.056$ ), other studies have found a loss of heterozygosity at this site (Poli-Frederico et al, 2000; dos Reis et al, 2002) and an association with poor prognosis (Ashman 
Table 3 Chromosomal locations of DNA gain in individual patients

\begin{tabular}{|c|c|c|c|c|c|}
\hline $\begin{array}{l}\text { ID } \\
\text { no. }\end{array}$ & Both samples, common gains & PT, unique gains & $\begin{array}{l}\text { Total no. } \\
\text { gains }\end{array}$ & LNM, unique gains & $\begin{array}{l}\text { Total no. } \\
\text { gains }\end{array}$ \\
\hline 1 & $3 q, 1|q| 3$ & |q25-qter, 6p22, 8q21-23,12p & 6 & $1 p 33-35,16,17,18 p, 19,20 q, 22$ & 9 \\
\hline 2 & $3 q$ & 7qcen-q32, ||$q|3| 8 q|| .2$, & 4 & $\mid q 21-32,22 q$ & 3 \\
\hline 3 & $\mid q 21-31,3 q 22$-qter, 5p, 8q, I|p|3-q22 & & 5 & $4 q \mid 3.1-13.3,6 q c e n-23,12 q 21.1-21.3,22 q$ & 9 \\
\hline 4 & $|q 25-3|$ & & I & $3 q, 6 q 21,8 q 22-24,18 q$ & 5 \\
\hline 5 & $|p 22,3 q 24-q t e r, 7 q 2|-31.2,|| q \mid 3$ & 6p22-pter & 5 & $5 p, 6 q c e n-15,13 q 21-22$ & 7 \\
\hline 6 & $3 q, 8,12 p \mid 1.2-q 23$ & $\begin{array}{l}5 p, 7 p|5-q 32,| 3 q \mid 4,14 q c e n-q 22 \\
|6 p||.2-12,| 8 p\end{array}$ & 9 & $\begin{array}{l}\mid p 22,2 q 22-32,4 \text { cen-q31, 5qcen-23, } \\
\text { 6qcen-23, 9p2।, I|p|3, |3q2|-3| }\end{array}$ & 11 \\
\hline 7 & & $7 q|1.2| 8 q \mid 1.2$, & 2 & $\begin{array}{l}2 p|6,2 q 22-q 32,3 q 25-q 26,4 p| 4-q 31 \\
5 q 21-q 23,6 q c e n-q 23,12 q 21,13 q 2-q 31\end{array}$ & 8 \\
\hline 8 & Iqcen-q32, 3q, 5p, 8q, II q22, & $2 q 24.3,9 q, 12 q 21.3,14 q 22-23$ & 9 & $13 q 21$ & 6 \\
\hline 9 & 5pcen-p|4,7cen, I2p & $3 q 25.2-q 25.3$ & 4 & 2q32.3, 6qcent-q12, 6q21 -q22.3, I Iq21 & 7 \\
\hline 10 & $\begin{array}{l}2 q 22-31,3 q 24-26,4 q c e n-q 31,6 q c e n-23 \\
8 q, 12 q 21\end{array}$ & $\begin{array}{l}|p 3|-22,5 p, 5 q|5-23,||p| 4 \\
|| q 2|-22,| 3 q,|8 q| 2\end{array}$ & 13 & & 6 \\
\hline $\mid 1$ & $\begin{array}{l}2 q 22-q 32,3 \text { cen-q13, 3q24-q27, 8q, } \\
12 q 21,13 q 21\end{array}$ & $2 p|3-p| 6,7 q \mid 1.2,12 p$ & 9 & $|p 22,4 q, 5 q 2|-22,6 q c e n-q 21,9 p 2 \mid$ & || \\
\hline 12 & $3 q$ & 6qcen-q21 & 2 & $|p 32-p 35,12 p| 3,16 p, 17 q \mid 2,19 q, 20 q, 22$ & 8 \\
\hline 13 & $\begin{array}{l}\text { Ipcen-p22, 2q22-32, 3q24-qter, } \\
\text { 4cen-q25, 6qcen-q22, I2q15-2I }\end{array}$ & $8 q 2|-23,9 q|,|p| 3,|4 q| 3$ & 10 & 13q21, 17q23-qter & 8 \\
\hline 14 & $\begin{array}{l}\text { 3q24-qter, 5p, 6p22-pter, 8q, } \\
13 q 31 \text {-qter, } 18\end{array}$ & |q32-qter, 6qcen-q16 & 8 & 5q34-qter, 7q1।.2, I5cen-q|4, 20p & 10 \\
\hline 15 & $\begin{array}{l}3 q 24-q 28,4 q c e n-q 21.1,5 p, 8 q 23 \\
13 q 21.2-q 21.3,18 p \mid 1.31 \text {-pter, } \\
22 q 12.2-q 13.2\end{array}$ & $\begin{array}{l}\text { 2p, 4p 16-pter, 7p21, 12p, } \\
16 p 13.2 \text {-pter, 17p13-pter }\end{array}$ & 13 & $20 q \mid 3.2$ & 8 \\
\hline 16 & $\begin{array}{l}|q, 2 p| 3-p 21,2 q 24-q 32,3 q, 6 q c e n-q 22 \\
7 \text { cen-q33, 8q, II } 1 \text { 13, I4q, I8p }\end{array}$ & 17cen-q21, 20cen-q12 & 12 & $9 q 31$ & $1 \mid$ \\
\hline 17 & $2 q 22-q 32,3 q, 4$ cen-q3।, 8q, ||$p|4-q| 3$ & $5 p, 12 p \mid 3$-pter, 19q & 8 & $\mid q 31,6 q 22-q 24,7 q 31.1-31.3,18 p$ & 9 \\
\hline 18 & $\begin{array}{l}\text { Iq2।.I-qter, 2q21.3-32.1, 3q2।-qter, } \\
5 p \mid 5.1 \text {-pter, 8q22.2-24.2, I5q15-26.। } \\
|8 p||.3| \text {-pter }\end{array}$ & $\begin{array}{l}2 p 14-16,6 p \mid 1.2 \text {-pter, 7pcent-15.3, } \\
7 q 33-q t e r, 7 q 21.1-21.3,12 p \\
16 q 12.1-23\end{array}$ & 14 & $\begin{array}{l}7 p 15.3-p 21,7 q 31.1-31.3,1 \mid \text { pcent-13, } \\
\text { |4qcent-13 }\end{array}$ & II \\
\hline 19 & $\begin{array}{l}\text { 2pcent-। 1.2, 2p 13-pter, 3q23-qter, 5p, } \\
9 p 21-p 22,9 q 22.2-q 33,14 q 24.1-q 32 \\
\text { I7p, I 7qcent-q23, I9pcent-p 13.1 }\end{array}$ & $\begin{array}{l}\text { 2q24.3-q32.1, 6p 1 1.2-p21.1, } \\
7 q 21.3-q 31.1,7 q 36,1 \mid \text { qcent-q13.3, } \\
12 \text { pcent-12.1, 22qcent-13.2 }\end{array}$ & 17 & $\begin{array}{l}|q 2|-23,7 p c e n t-p|4,| 0 p|| .|-p||.2,| 0 p \mid 5 \text {, } \\
|2 q c e n t-q 2| .|,| 4 q c e n t-q 2|,| 8 p\end{array}$ & 17 \\
\hline 20 & $\begin{array}{l}2 q 24.1-q 32,3 q c e n t-13.1,7 p \mid 4-p t e r \\
7 q|1.23-q 22,12 p| 3.3,13 q 33 \\
\mid 4 q 24.2-q 32.1,17 p\end{array}$ & $\begin{array}{l}3 q 28,4 q 2 \mid .2-q 24,5 p \\
|3 q| 2 .|-q| 2.2,|8 p||.3| \text {-pter }\end{array}$ & 13 & 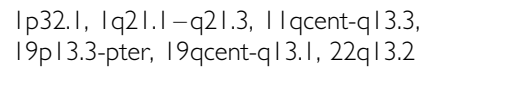 & 14 \\
\hline 21 & $\begin{array}{l}|q 3|, 3 q 2 \mid-q 27,5 p, 8 q 22.1-q 24.1 \\
|| q|2-q| 4.2, \mid 2 p\end{array}$ & $7 q 21.2-q 21.3$ & 7 & $14 q, 16 p \mid 3.3,16 q$ & 9 \\
\hline 22 & $\begin{array}{l}\text { Iq25-32.1, 3q, 7p 15.2-pter, 8q23-q24.2, } \\
9 q 33-34.2,12 p, 16 q 23\end{array}$ & 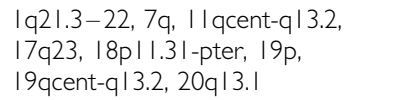 & 15 & $\begin{array}{l}\text { Ip36.3-pter, I0p |5-pter, I | p | 5.5-pter, } \\
\text { |6p|3.3, |9q |3.4-qter, } 2 \text { | q22.2, 22q |3.2 }\end{array}$ & 14 \\
\hline 23 & $\begin{array}{l}\text { I qcen-q31, 5p, 8q22.2-q24.2, I2p, } \\
\text { I2qcent-q21.3, I4q32.2, I7q21.2-q24, } \\
\text { I9p।3.3-pter }\end{array}$ & Ip32.I-p32.3, 3q35-q36, 9q34.2 & II & $\begin{array}{l}\text { 2pcen-p|6, 2q21.2-q3।,3p||-p|2, } \\
3 q 21-q 28,6 p c e n-p \mid 2,6 q, 7 q 21.1 \\
7 q 31.1-q 35,9 p 23-p t e r, 10 p \mid 5 \\
15 q 21.1-q 25,18 p, 22 q|3.2-q| 3.3\end{array}$ & 16 \\
\hline
\end{tabular}

PT = primary tumour, LNM = lymph node metastasis.

et al, 2003). Two genes are located on 22q in close proximity to each other: STMY3 at 22q11.2 and the BCR gene. The STMY3 gene encodes for stromelysin III, a member of the matrix metalloproteinase family that is involved in the physiological and pathological control of extracellular matrix remodelling. Stromelysin III has been found to be overexpressed in the stromal cells of invasive breast carcinoma (Nakopoulou et al, 2002). Whether this chromosomal gain on $22 \mathrm{q}$ only occurred in a few cells in the PT, and therefore, was not detectable by $\mathrm{CGH}$, but gave this subclone a competitive advantage to metastasise or whether this expression occurred after migration is not clear from this study. Future work focusing on such genes in the PT will hopefully clarify their importance in the development of metastasis.

The CGH results from our work and the previous two major studies discussed here have upheld the clonality of the metastatic cells; but no obvious single or group of aberrations appears to cause metastatic spread in HNSCC, that is, a distinct, common tumour progression pathway is not evident. It must be noted that 18 of 23 of our cohort had advanced T3 or T4 carcinomas, and thus more incidental aberrations may be present and obscure the genotype for metastatic progression. A similar preponderance towards more advanced tumours is true for Bockmuhl's cohort.

Another theory is that some primaries are 'preconfigured to metastasise' by the time of diagnosis (Ramaswamy et al, 2003). Both Welkoborsky et al (2000) and Bockmuhl et al (2002) attempted to address the differences between nonmetastasising and metastasising HNSCC in their studies; however, disparate results have been reported. Welkoborsky and co-workers reported over-representation of DNA on $1 p$ and $7 p$ exclusively in node-negative PT and over-representation of DNA on 1q, $11 \mathrm{q}$ and $22 \mathrm{q}$ were in node-positive PT. Bockmuhl et al (1997) analysed 29 metastasising and 19 nonmetastasising HNSCC, and showed a preferential association between gain of DNA on $5 p, 6 p$ and $7 p$ and node-negative PT. Node-positive tumours were characterised by deletions on chromosomes $7 \mathrm{q}, 10 \mathrm{q} 11 \mathrm{p}$, $11 \mathrm{q} 15 \mathrm{q}$ and $20 \mathrm{p}$, as well as gains on chromosomes $19 \mathrm{q}$ and 
Table 4 Chromosomal locations of DNA loss in individual patients

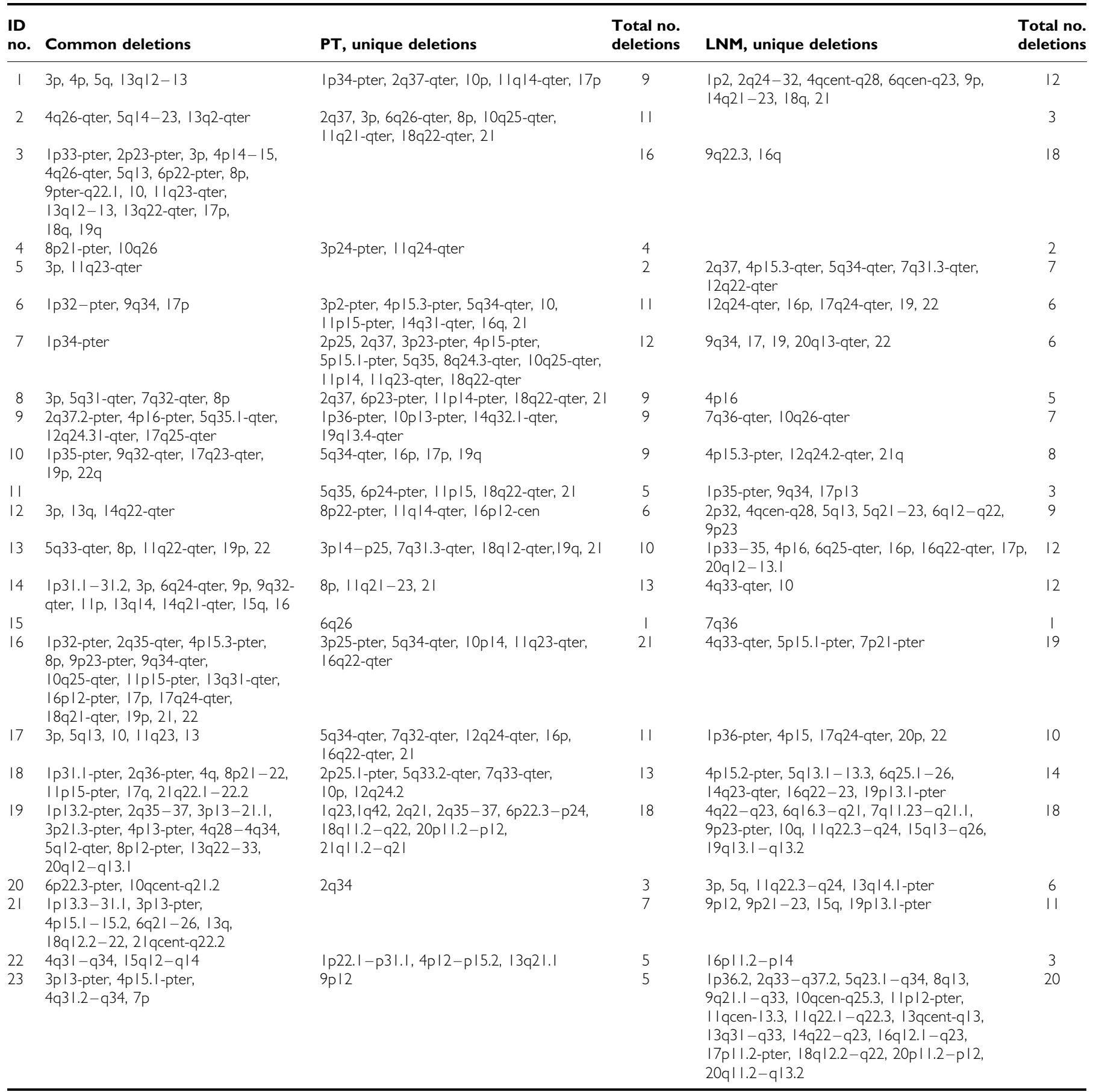

$\mathrm{PT}=$ primary tumour, $\mathrm{LNM}=$ lymph node metastasis.

20q. The more recent, larger, study by Bockmuhl et al (2002) that included some of the patients analysed previously also found an association between deletions of $10 \mathrm{q}, 11 \mathrm{p}$ and 11qter and node-positive PT. Whether these differences are simply due to the relatively small number of tumours studied or truly reflect the complex genetic make-up of HNSCC remain to be elucidated.

Although the technique of CGH has limitations, that is, balanced translocations, rearrangements and/or ploidy change cannot be recognised, and no obvious genetic metastatic signature could be identified; the $\mathrm{CGH}$ data from all three studies do confirm the clonal relationship of the primary and LNM. Furthermore, CGH remains a useful tool to guide the application of higherresolution techniques such as loss of heterozygosity studies and mutational analysis, ultimately speeding up the identification of the critical genes involved in HNSCC tumorigenesis. In the future, once such genes have been categorised, new technologies like DNA microarrays, which simultaneously analyse the expression of vast repertoires of genes in individual tumours, will be used to predict the clinical characteristics of a patient's tumour at the time of diagnosis allowing the optimisation of the treatment regimen. 

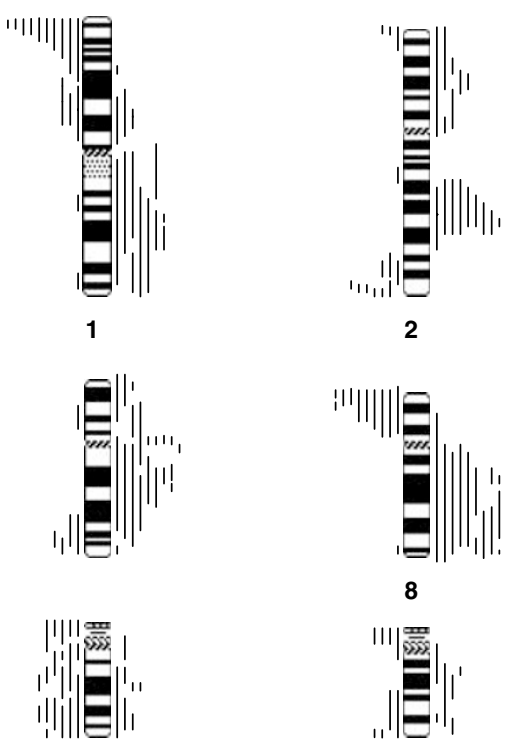

13

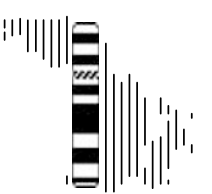

8

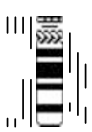

14

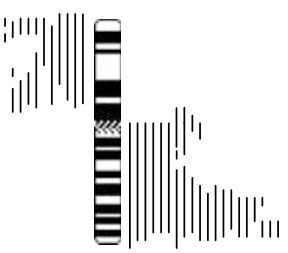

3

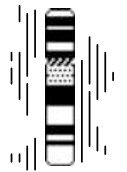

9

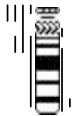

15

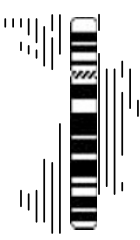

4

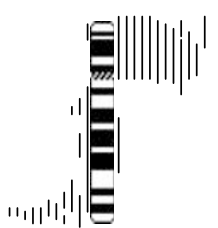

5

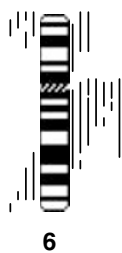

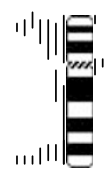

10

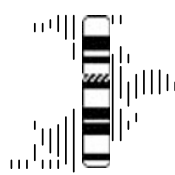

11

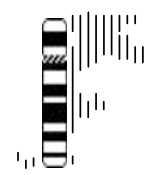

12

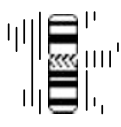

16

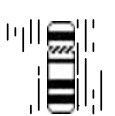

17

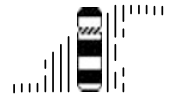

18
!

19

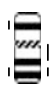

20

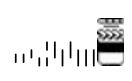

21
11

22

Figure I Ideogram to show the location of all the deletions and gains found in all 23 primary tumours. Lines drawn to the left of the ideogram represent the location of regions of deletion or loss. Lines drawn to the right represent the location of gains or amplifications of chromosomal material.
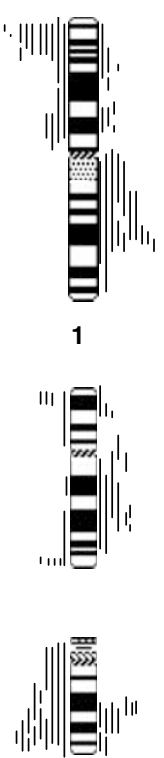

13
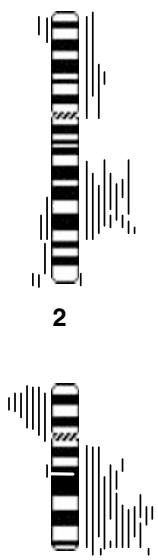

8

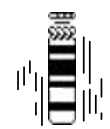

14
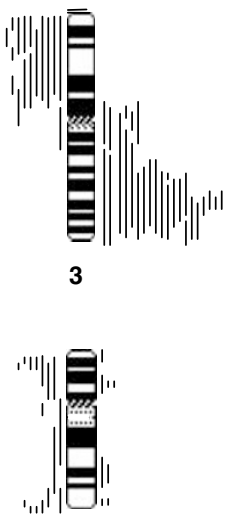

9

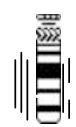

15

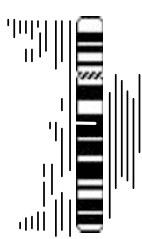

4

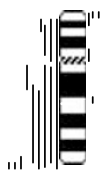

10

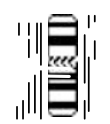

16

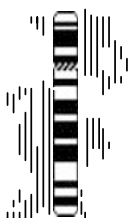

5

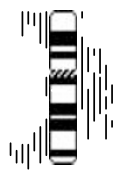

11

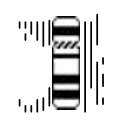

17

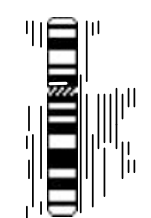

6

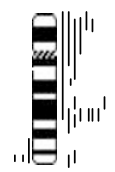

12

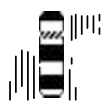

18

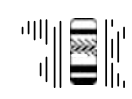

19

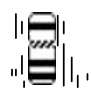

20
|, |

21

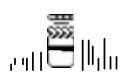

22

Figure 2 Ideogram to show the location of all the deletions and gains found in all 23 metastatic lymph node samples. Lines drawn to the left of the ideogram represent the location of regions of deletion or loss. Lines drawn to the right represent the location of gains or amplifications of chromosomal material. 


\section{REFERENCES}

Ashman JNE, Patmore HS, Condon LT, Cawkwell L, Stafford ND, Greenman J (2003) Prognostic value of genomic alterations in head and neck squamous cell carcinoma detected by comparative genomic hybridization. Br J Cancer 89: $864-869$

Bergamo NA, Rogatto SR, Poli-Frederico RC, Reis PP, Kowalski LP, Zielenska M, Squire JA (2000) Comparative genomic hybridization analysis detects frequent over- representation of DNA sequences at 3q, $7 \mathrm{p}$, and $8 \mathrm{q}$ in head and neck carcinomas. Cancer Genet Cytogenet 119: $48-55$

Bockmuhl U, Schluns K, Schmidt S, Matthias S, Petersen I (2002) Chromosomal alterations during metastasis formation of head and neck squamous cell carcinoma. Genes Chromosomes Cancer 33: 29-35

Bockmuhl U, Wolf G, Schmidt S, Schwendel A, Jahnke V, Dietel M, Petersen I (1998) Genomic alterations associated with malignancy in head and neck cancer. Head Neck 20: $145-151$

dos Reis PP, Poli-Frederico RC, dos Santos RM, Nishimoto IN, Kowalski LP, Rogatto SR (2002) Distinct regions of loss of heterozygosity on 22q in different sites of head and neck squamous cell carcinomas. Med Sci Monit 8: BR89-BR94

Gollin SM (2001) Chromosomal alterations in squamous cell carcinomas of the head and neck: window to the biology of disease. Head Neck 23: $238-253$

Huang Q, Yu GP, McCormick SA, Mo J, Datta B, Mahimkar M, Lazarus P, Schaffer AA, Desper R, Schantz SP (2002) Genetic differences detected by comparative genomic hybridization in head and neck squamous cell carcinomas from different tumor sites: construction of oncogenetic trees for tumor progression. Genes Chromosomes Cancer 34: 224-233

Jeuken JWM, Sprenger SHE, Wesseling P (2002) Comparative genomic hybridization: practical guidelines. Diagn Mol Pathol 11: 193-203

Jin C, Jin Y, Wennerberg J, Akervall J, Dictor M, Mertens F (2002) Karyotypic heterogeneity and clonal evolution in squamous cell carcinomas of the head and neck. Cancer Genet Cytogenet 132: 85-96

Kujawski M, Sarlomo-Rikala M, Gabriel A, Szyfter K, Knuutila S (1999) Recurrent DNA copy number losses associated with metastasis of larynx carcinoma. Genes Chromosomes Cancer 26: 253-257

Kuukasjarvi T, Karhu R, Tanner M, Kahkonen M, Schaffer A, Nupponen N, Pennanen S, Kallioniemi A, Kallioniemi OP, Isola J (1997) Genetic heterogeneity and clonal evolution underlying development of asynchronous metastasis in human breast cancer. Cancer Res 57: $1597-1604$

Nakopoulou L, Panayotopoulou EG, Giannopoulou I, Alexandrou P, Katsarou S, Athanassiadou P, Keramopoulos A (2002) Stromelysin-3 protein expression in invasive breast cancer: relation to proliferation, cell survival and patients' outcome. Mod Pathol 15: 1154-1161

Ono I (1986) Head and neck cancer: choice of treatment in relation to clinical and pathological findings. Gan To Kagaku Ryoho 13: 18-23

Poli-Frederico RC, Bergamo NA, Reis PP, Kowalski LP, Zielenska M, Squire JA, Rogatto SR (2000) Chromosome 22q a frequent site of allele loss in head and neck carcinoma. Head Neck 22: 585-590

Ramaswamy S, Ross KN, Lander ES, Golub TR (2003) A Molecular signature of metastasis in primary solid tumors. Nat Genet 33: 49-54

Stafford ND, Ashman JN, MacDonald AW, Ell SR, Monson JR, Greenman J (1999) Genetic analysis of head and neck squamous cell carcinoma and surrounding mucosa. Arch Otolaryngol Head Neck Surg 125: $1341-1348$

Struski S, Doco-Fenzy M, Cornillet-Lefebvre P (2002) Compilation of published comparative genomic hybridization studies. Cancer Genet Cytogenet 135: 63-90

Veltman JA, Hopman AH, van der Vlies SA, Bot FJ, Ramaekers FC, Manni JJ (1998) Double-target fluorescence in situ hybridization distinguishes multiple genetically aberrant clones in head and neck squamous cell carcinoma. Cytometry 34: 113-120

Welkoborsky HJ, Bernauer HS, Riazimand HS, Jacob R, Mann WJ, Hinni ML (2000) Patterns of chromosomal aberrations in metastasizing and nonmetastasizing squamous cell carcinomas of the oropharynx and hypopharynx. Ann Otol Rhinol Laryngol 109: 401-410

Zitzelsberger H, Lehman L, Werner M, Bauchinger M (1997) Comparative genomic hybridisation for the analysis of chromosomal imbalances in solid tumours and haematological malignancies. Histochem Cell Biol 108: $403-417$ 